\title{
Comparison of Individual- and Bulked-Samples-Based Approaches Using RAPD and ISSR Markers for Identifying Genetic Relationships in Brassica Cultivars
}

\author{
Yu Takahashi ${ }^{1 \S \dagger}$, Hiroyoshi Iwata ${ }^{2 \S^{\ddagger}}$, Yoshihito Takahata ${ }^{1}$ and Kenji Wakui ${ }^{3 *}$ \\ ${ }^{1}$ Faculty of Agriculture, Iwate University, 3-18-8 Ueda, Morioka, Iwate 020-8550, Japan \\ ${ }^{2}$ Department of Information Science and Technology, National Agricultural Research Center, \\ 3-1-1 Kannondai, Tsukuba, Ibaraki 305-8666, Japan \\ ${ }^{3}$ Department of Bioresource Development, Tokyo University of Agriculture, \\ 1737 Funako, Atsugi, Kanagawa 243-0034, Japan
}

Received August 1, 2018; accepted December 8, 2018

\begin{abstract}
Summary Random amplified polymorphic DNA (RAPD) and inter-simple sequence repeat (ISSR) variation among 24 cultivars of four Brassica species (B. rapa, B. juncea, B. napus, and B. oleracea) was examined using individual- and bulked-samples-based approaches. In both the approaches, eight plants were sampled for each cultivar, and were amplified individually and as bulked DNA, respectively. In total, 305 and 422 bands were scored in the individual- and bulked-samples-based approaches, respectively, and almost all the bands (99.8$100 \%$ ) were polymorphic. Based on the individual-samples dataset, the within cultivar variation was smaller than the among cultivars variation, leading to a distribution reflecting genome compositions of each cultivar with principal coordinates analysis (PCoA) and unweighted pair-group method with arithmetic average (UPGMA) analysis. Although PCoA and UPGMA analysis based on bulked-samples data clustered the cultivars into groups with more emphasized variance among species than the results obtained by the individual-based approach, both PCoA plots and dendrograms of the individual- and bulked-samples-based approaches, respectively, were highly correlated with each other. These findings indicate that the number of individuals used to profile each cultivar can be reduced to eight per cultivar for analysis of the genetic variability in Brassica using RAPD and ISSR polymorphism, and the bulked-samples-based approach can be used to describe the genetic relationship among Brassica cultivars.
\end{abstract}

Key words Random amplified polymorphic DNA, RAPD, Inter-simple sequence repeat, ISSR, Individualbased approach, Bulked-samples-based approach, Brassica.

Molecular markers have proved valuable in crop breeding, especially in studies on genetic diversity and for assessing relationships in a number of crop species. Among the different molecular genetic markers, RAPD and ISSR markers have been used to generate vast quantities of data, resulting in their rapid application for addressing a diverse range of biological questions (Semagn et al. 2006, Agarwal et al. 2008, Verma et al. 2016, Kalia et al. 2017). Because of their efficiency and convenience, these techniques have been applied to taxonomic comparisons of many plant species (Fernández et al. 2002, Sudupak 2004, Wu et al. 2004, Liu and Wang 2006, Han and Wang 2010, Sultana and Alam 2016, Dasgupta et al. 2018). To estimate the genetic

\footnotetext{
*Corresponding author, e-mail: wakuik@nodai.ac.jp

${ }^{\dagger}$ Present address: Genetic Resources Center, National Agriculture and Food Research Organization, Tsukuba, Ibaraki 305-8602, Japan

₹ Present address: Graduate School of Agricultural and Life Sciences, The University of Tokyo, Tokyo 113-8657, Japan

$\S$ These authors contributed equally to this work.

DOI: $10.1508 /$ cytologia. 84.119
}

distance between cultivars or populations, analyzing a large number of accessions individually within a cultivar or population is desired. Especially, in the estimation of the genetic structure of allogamous species, the diversity existing among individuals within cultivars or populations should be taken into account (Ghérardi et al. 1998, Raimondo et al. 2012). However, these approaches are laborious and impractical if a large number of populations is to be characterized.

The bulked samples approach is based on mixing equal quantities of genomic DNA, and can reduce the experimental effort, as the large size of a collection makes its management and use difficult (Michelmore et al. 1991, Kongkiatngam et al. 1996, Taški-Ajduković et al. 2014). Hence, this approach has been widely used for estimating genetic variation and relationships among species, cultivars, and populations, such as alfalfa (Yu and Pauls 1993, Segovia-Lerma et al. 2003, TaškiAjduković et al. 2014), red clover (Kölliker et al. 2001, Dias et al. 2008), Brumus catharticus (Puecher et al. 2001), radish (Muminović et al. 2005, Wang et al. 2008), 
B. napus (Dulson et al. 1998), and B. oleracea (Lázaro and Aguinagalde 1998, Divaret et al. 1999), and the efficacy of this strategy has been examined. The bulked samples approach simplifies the marker profile of an individual cultivar or population because it favors the detection of consensus fragments (i.e., common alleles) in each population (Michelmore et al. 1991, Yu and Pauls 1993). Segovia-Lerma et al. (2003) reported that this approach may reflect a population's general genetic composition more accurately compared to the evaluation of fewer individual genotypes. Although an appropriate bulk size, reflecting genetic diversity existing between individuals within the population, depends on the degree of heterozygosity in species, the relationship between an appropriate bulk size and the degree of heterozygosity has not been fully examined for each plant species analyzed in this study.

The genus Brassica contains some of the most important arable and forage crop species, such as turnip (B. rapa), leaf mustard (B. juncea), oil seed rapa ( $B$. napus), and cabbage ( $B$. oleracea). Their genomes have been denoted as A, B, and $\mathrm{C}$, respectively, and the hybrid taxa, B. napus, B. juncea, and B. carinata, are the known amphidiploids of $B$. rapa $\times B$. oleracea $(\mathrm{AC}), B$. rapa $\times B$. nigra $(\mathrm{AB})$, and $B$. oleracea $\times B$. nigra $(\mathrm{BC})$, respectively (U 1935). Among the Brassica species, $B$. rapa and $B$. oleracea are allogamous species, owing to their self-incompatible nature, and are expected to be genetically heterogeneous, especially in the indigenous varieties. In a previous study, we reported the congruity between genetic similarities among cultivars, calculated from the data based on individual and bulked population samples, to assess genetic relationships between Brassica cultivars, including heterogeneous species (Wakui et al. 2009). In the above-mentioned study, we also determined that the number of plantlets that should be analyzed per cultivar using RAPD and ISSR analysis is 37 , for each of the six cultivars of Japanese turnip ( $B$. rapa ssp. rapa). In the present study, to apply the results described in the previous report and to evaluate the efficacy of the method proposed therein, we compared the genetic relationships among 24 Brassica cultivars and determined the genetic variability, inferred by individual- and bulked-samples-based approaches, using RAPD and ISSR markers.

\section{Materials and methods}

\section{Plant materials and DNA preparation}

Twenty-four cultivars, including 17 traditional and 7 commercial cultivars selected from four cultivated Brassica species, were used in this study (Table 1). Among them 17 cultivars were of $B$. rapa, two each were of $B$. juncea and $B$. napus, and three were of B. oleracea. $B$. rapa was represented by six subspecies, three of ssp. pekinensis, nine of ssp. rapa, one each of ssp. chinensis, japonica and oleifera, and two of ssp. narinosa. Eight seedlings per cultivar were randomly selected and the

Table 1. Brassica cultivars included in the present study.

\begin{tabular}{|c|c|c|c|c|c|}
\hline Species & Genome & ID & Cultivars & Type & $\mathrm{He} \pm \mathrm{SD}^{\mathrm{a}}$ \\
\hline \multirow[t]{3}{*}{ B. rapa ssp. pekinensis } & AA & A & Matsusima-shin-nigouhakusai & Commercial & $0.073 \pm 0.166$ \\
\hline & & $\mathrm{B}$ & Kanazawadaigo-kettukyuhakusai & Traditional & $0.092 \pm 0.179$ \\
\hline & & $\mathrm{C}$ & Tokyo-bekana & Traditional & $0.116 \pm 0.191$ \\
\hline \multirow[t]{9}{*}{ B. rapa ssp. rapa } & & $\mathrm{D}$ & Maruba-komatsuna & Traditional & $0.117 \pm 0.185$ \\
\hline & & $\mathrm{E}$ & Kiso-benikabu & Traditional & $0.131 \pm 0.196$ \\
\hline & & $\mathrm{F}$ & Kamo-sugukina & Traditional & $0.102 \pm 0.177$ \\
\hline & & $\mathrm{G}$ & Hinoguchi-kabu & Traditional & $0.091 \pm 0.176$ \\
\hline & & $\mathrm{H}$ & Hinona-kabu & Traditional & $0.092 \pm 0.173$ \\
\hline & & $\mathrm{I}$ & Tennoji-kabu & Traditional & $0.124 \pm 0.192$ \\
\hline & & $\mathrm{J}$ & Hakuba & Commercial & $0.044 \pm 0.132$ \\
\hline & & $\mathrm{K}$ & Kuretsubo-kabu & Traditional & $0.083 \pm 0.172$ \\
\hline & & $\mathrm{L}$ & Nozawana & Traditional & $0.114 \pm 0.190$ \\
\hline B. rapa $\mathrm{ssp}$. chinensis & & $\mathrm{M}$ & Yukishiro-taisai & Traditional & $0.118 \pm 0.192$ \\
\hline B. rapa ssp. japonica & & $\mathrm{N}$ & Bansei-sensuji-mizuna & Traditional & $0.106 \pm 0.185$ \\
\hline \multirow[t]{2}{*}{ B. rapa ssp. narinosa } & & $\mathrm{O}$ & Bitamin-na & Commercial & $0.099 \pm 0.182$ \\
\hline & & $\mathrm{P}$ & Tijimi-na & Traditional & $0.084 \pm 0.174$ \\
\hline B. rapa ssp. oleifera & & $\mathrm{Q}$ & Hayachine-na & Traditional & $0.111 \pm 0.188$ \\
\hline \multirow[t]{2}{*}{ B. juncea } & AABB & $\mathrm{R}$ & Kigarashi-na & Traditional & $0.093 \pm 0.183$ \\
\hline & & $\mathrm{S}$ & Miike-takana & Traditional & $0.033 \pm 0.117$ \\
\hline \multirow[t]{2}{*}{ B. napus } & $\mathrm{AACC}$ & $\mathrm{T}$ & Senpousai-nigou & Commercial & $0.055 \pm 0.145$ \\
\hline & & $\mathrm{U}$ & Miyauchi-na & Traditional & $0.055 \pm 0.147$ \\
\hline \multirow[t]{4}{*}{ B. oleracea } & $\mathrm{CC}$ & $\mathrm{V}$ & Delicious & Commercial & $0.045 \pm 0.135$ \\
\hline & & $\mathrm{W}$ & Watanabeseikou & Commercial & $0.088 \pm 0.173$ \\
\hline & & $\mathrm{Z}$ & Stick senyoru & Commercial & $0.042 \pm 0.129$ \\
\hline & & & & Mean & $0.088 \pm 0.170$ \\
\hline
\end{tabular}

${ }^{\text {a }}$ The expected heterozygosity (He) was estimated by 305 loci of RAPD and ISSR using eight individuals per cultivar. SD means Standard deviation. 
first leaf of each of the seedlings was sampled from each cultivar. These leaves were frozen in liquid nitrogen and stored at $-80^{\circ} \mathrm{C}$. DNA extraction was carried out by the cetyltrimethylammonium bromide method (Rogers and Bendich 1988). DNA concentration was determined using an UV-visible spectrophotometer (UV-1600, Shimadzu). In the individual population sample-based approach, DNA of each of the eight individuals per cultivar was used independently as a template for PCR. On the other hand, in the bulked-samples-based approach, DNA samples were prepared by mixing $500 \mathrm{ng}$ of DNA from each of the eight individuals per cultivar, and $20 \mathrm{ng}$ DNA was used for PCR.

\section{DNA amplification and data analysis}

RAPD and ISSR primers used in this study were the same as those reported by Wakui et al. (2009). RAPD and ISSR analyses were performed using ten 10-mer random oligonucleotides (Eurofins Genomics) and ten selected ISSR primers from primer set No. 9 (Biotechnology Laboratory of University of British Columbia, Vancouver, B.C., Canada) (Table 2). The RAPD and ISSR fragments were manually scored as present (1) or absent (0). Only the distinct major bands were chosen for this study. To estimate the variation within populations, expected heterozygosity was calculated based on allele frequencies of respective loci for each population with data from individual samples. Analysis of molecular variance (AMOVA; Excoffier et al. 1992) was performed using GenAlEx v.6 (Peakall and Smouse 2012) to assess RAPD and ISSR variations among and within species

Table 2. Sequences of primers employed and the number of scored polymorphic bands based on RAPD and ISSR analysis.

\begin{tabular}{|c|c|c|c|}
\hline \multirow{2}{*}{$\begin{array}{l}\text { Name of } \\
\text { primers }\end{array}$} & \multirow{2}{*}{$\begin{array}{l}\text { Sequences } \\
\quad\left(5^{\prime}-3^{\prime}\right)\end{array}$} & \multicolumn{2}{|c|}{ No. of polymorphic bands } \\
\hline & & $\begin{array}{c}\text { Individual-based } \\
\text { approach }\end{array}$ & $\begin{array}{l}\text { Bulked-samples- } \\
\text { based approach }\end{array}$ \\
\hline OPA-1 & CAGGCCCTTC & 14 & 12 \\
\hline OPA-2 & TGCCGAGCTG & 15 & 9 \\
\hline OPA-3 & AGTCAGCCAC & 14 & 10 \\
\hline OPA-4 & AATCGGGCTG & 19 & 21 \\
\hline OPA-7 & GAAACGGGTG & 14 & 15 \\
\hline OPA-8 & GTGACGTAGG & 15 & 6 \\
\hline OPA-9 & GGGTAACGCC & 11 & 4 \\
\hline OPA-10 & GTGATCGCAG & 13 & 17 \\
\hline OPA-11 & CAATCGCCGT & 12 & 13 \\
\hline OPA-20 & GTTGCGATCC & 13 & 18 \\
\hline UBC-807 & $(\mathrm{AG})_{8} \mathrm{~T}$ & 20 & - \\
\hline UBC-808 & $(\mathrm{AG})_{8} \mathrm{C}$ & 20 & 50 \\
\hline UBC-810 & $(\mathrm{GA})_{8} \mathrm{~T}$ & 20 & 55 \\
\hline UBC-811 & $(\mathrm{GA})_{8} \mathrm{C}$ & 17 & 26 \\
\hline UBC-812 & $(\mathrm{GA})_{8} \mathrm{~A}$ & 17 & 31 \\
\hline UBC-813 & $(\mathrm{CT})_{8} \mathrm{~T}$ & 14 & 32 \\
\hline UBC-814 & $(\mathrm{CT})_{8} \mathrm{~A}$ & 14 & 21 \\
\hline UBC-815 & $(\mathrm{CT})_{8} \mathrm{G}$ & 20 & 29 \\
\hline UBC-822 & $(\mathrm{TC})_{8} \mathrm{~A}$ & 12 & 22 \\
\hline \multirow[t]{2}{*}{ UBC-823 } & $(\mathrm{TC})_{8} \mathrm{C}$ & 11 & 31 \\
\hline & Total & 305 & 422 \\
\hline
\end{tabular}

for the bulked-samples-based approach, and among species as well as, among and within cultivars for the individual-samples approach. To visualize the relationship among the cultivars, PcoA (Gower 1966) was performed using GenAlEx v.6 (Peakall and Smouse 2012). Genetic relationships among the cultivars were investigated by cluster analysis using the UPGMA using MEGA ver. 7.0 (Tamura et al. 2007) based on genetic distances (Nei 1972) calculated by the genetic identity matrix for the individual method and by genetic distances calculated with 1-JACC ARD formula for the bulked-samplesbased approach.

\section{Results}

Ten RAPD and ISSR primers used in this study produced good amplification products. The exception was primer UBC-807, used in the bulked-samples-based approach, which did not produce any clear bands and whose data were, therefore, discarded. Details of the primers are listed in Table 2. In the individual-based approach, the amplification of eight individual DNA samples per primer revealed clear variations within each variety (Fig. 1a). The band pattern of each variety was relatively similar within and among the $B$. rapa subspecies, compared with that among different Brassica species. The differences in the band patterns among varieties were more simply shown in the bulked-samplesbased approach (Fig. 1b). Although the band pattern was the sum of the variation within the variety most detected by the individual method in bulk, there was also a band that was not detected. The PCR products were scored manually and independently, and the faint bands were excluded. The total number of bands scored was 305 and 422 in the individual- and bulked-samples-based approaches, respectively.

Based on individual-samples data, the expected heterozygosity values within each cultivar were calculated, which ranged from 0.033 to 0.131 , whereas the average value in all the cultivars was 0.088 (Table 1). The results of AMOVA also revealed that the variation among the individuals within a cultivar was relatively low (24\%) and most of the variation was responsible for the genetic variance among cultivars (40\%) in the individual-based approach (Table 3 ). On the other hand, the variation (53\%) among species in the bulked-samples-based approach was higher than that in the individual-based approach $(36 \%)$.

PCoA of the individual- and bulked-samples data clustered the 24 cultivars into roughly four groups, reflecting genome compositions and species taxa (Fig. $2 \mathrm{a}, \mathrm{b}$ ). Coordinate 1 , which accounted for $45 \%$ and $41 \%$ in the individual- and bulked-samples-based approach, respectively, resulted in the separation of four species. The known allopolyploid, B. napus, was observed to be located midway between its putative parent species, $B$. 
(a)

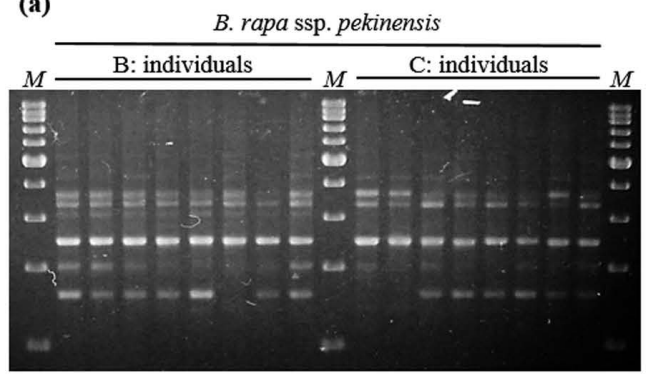

B. rapa ssp. chinensis
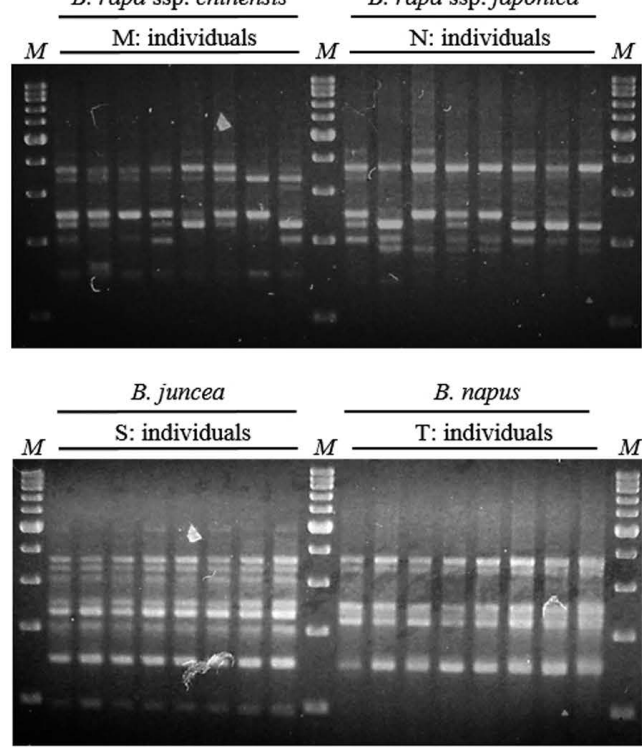

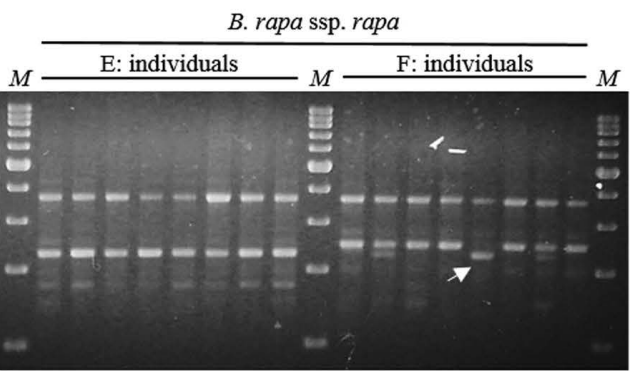

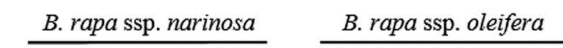

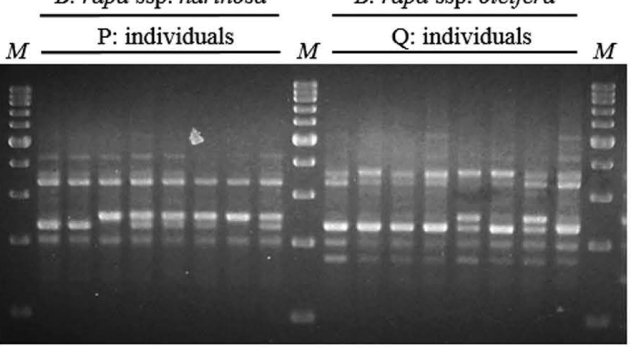

B. oleracea

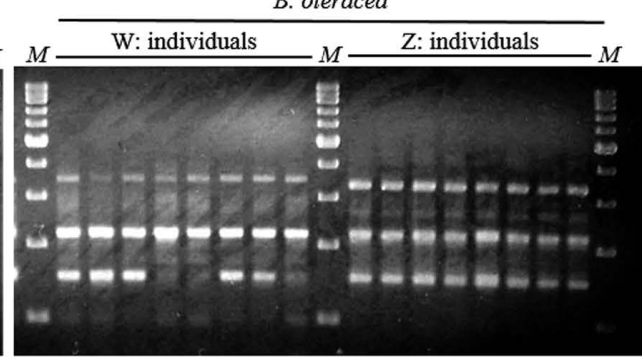

(b)

Each bulk

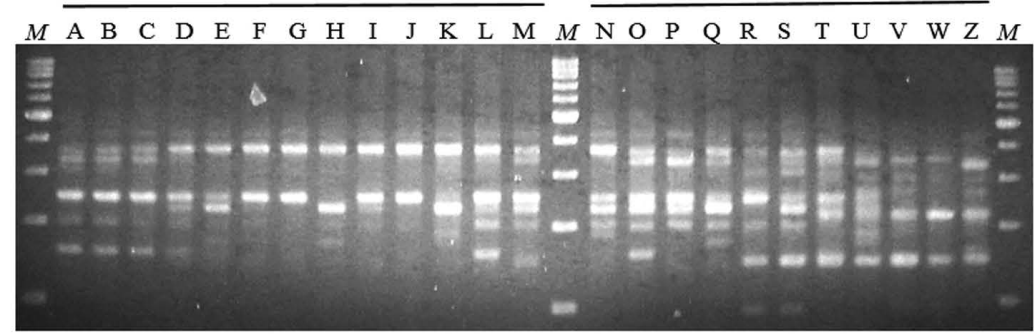

Fig. 1. RAPD band patterns produced by primer OPA-2 for eight individual samples (a) and a bulked sample (b) of Brassica cultivars. (a) Band patterns shown for 12 cultivars containing six B. rapa subspecies (B, C, E, F, M, N, P, and Q) and B. juncea (S), B. napus $(\mathrm{T})$, and B. oleracea (W and $\mathrm{Z}$ ). The arrow (a; F: individuals) shows a rare band detected in the individual-based approach. $M$ is a 500 -bp ladder DNA.

Table 3. Analysis of molecular variance (AMOVA) for individual-based and bulked-samples-based approaches using RAPD and ISSR.

\begin{tabular}{lcccccc}
\hline \hline Source & $\begin{array}{c}\text { Degree of } \\
\text { freedom }\end{array}$ & Sum of squares & Mean of squares & $\begin{array}{c}\text { Estimates of } \\
\text { variance }\end{array}$ & Variation (\%) & Probability \\
\hline Individual-based approach & & & & & & \\
$\quad$ Among species & 3 & 2090.91 & 696.97 & 17.63 & 36 & $<0.01$ \\
$\quad$ Among cultivars & 20 & 3364.10 & 168.20 & 19.53 & 40 & $<0.01$ \\
$\quad$ Within cultivars & 168 & 2003.88 & 11.93 & 11.93 & 24 & \\
$\quad$ Total & 191 & 7458.88 & & 49.09 & 100 & \\
Bulked-samples-based approach & & & & & & \\
$\quad$ Among species & 3 & 383.37 & 127.79 & 27.58 & 53 & \\
$\quad$ Within species & 20 & 487.22 & 24.36 & 24.36 & 47 & \\
$\quad$ Total & 23 & 870.58 & & 51.94 & 100 & \\
\hline
\end{tabular}


(a)

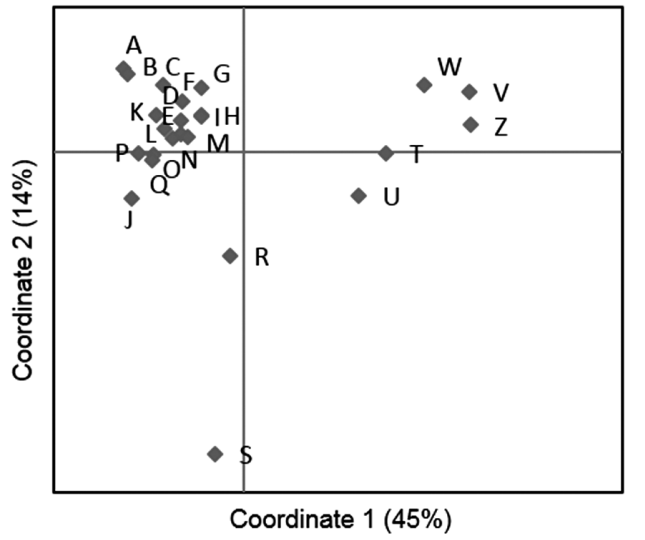

(c)

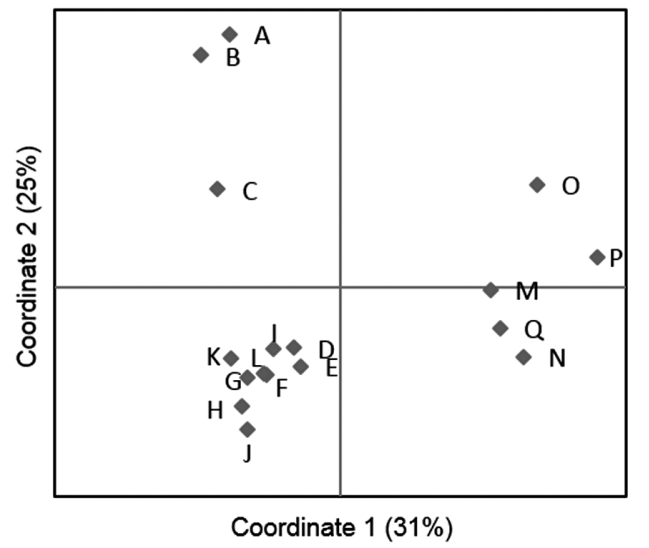

(b)

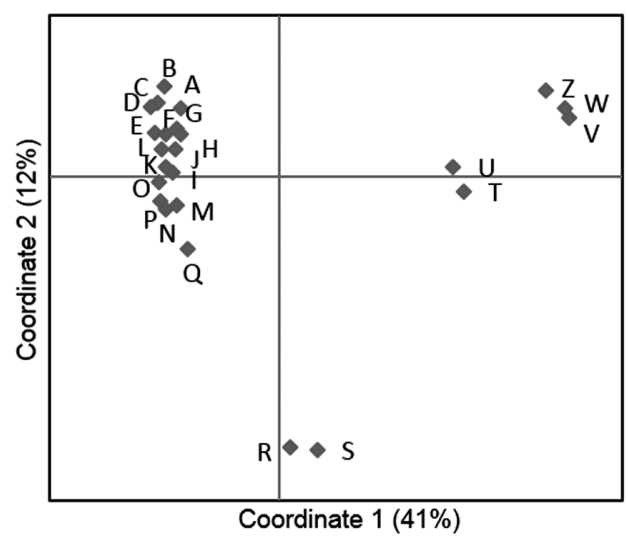

(d)

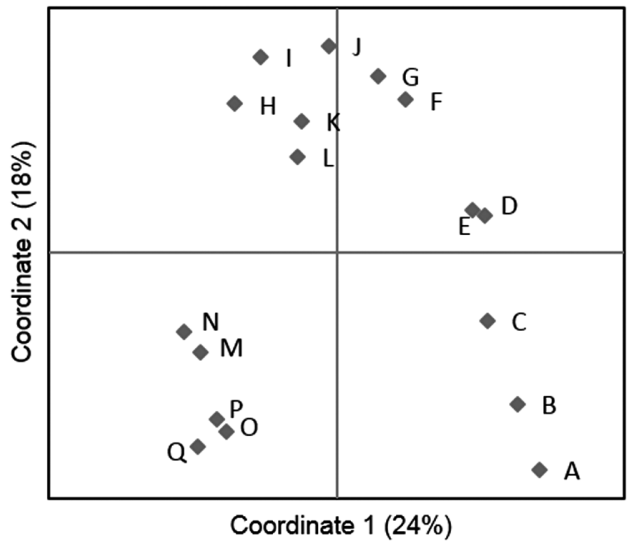

Fig. 2. Scatter diagrams of the first two coordinates from the principal coordinate analysis (PCoA) of 24 cultivars (a and b) and cultivars of B. rapa (c and d) using RAPD and ISSR. a and c: Individual-based approach, b and d: bulked-samples-based approach. Each cultivar is indicated by a plant ID (defined in Table 1).

rapa and B. oleracea. Coordinate 2 accounted for $14 \%$ and $12 \%$ in the individual- and bulked-samples-based approaches, respectively. Brassica juncea, which included unique B genome in our samples, was separated from all other species along the second axis. The genetic relationships among the four species fit closely between both the PCoA plots, although variance among the species rather than within the species was more emphasized in the bulked-samples-based approach. Closer examination of the PCoA analysis revealed the grouping of taxa within the B. rapa cluster containing six subspecies (Fig. $2 \mathrm{c}, \mathrm{d})$. Coordinates 1 and 2 accounted for $31 \%$ and $25 \%$ of the variation, respectively, in the individual-based approach. The $B$. rapa cultivars were largely separated into three groups consisting of ssp. pekinensis, ssp. rapa, and a group of ssp. chinensis, japonica, and oleifera. On the other hand, the coordinate 1 and 2 accounted for $24 \%$ and $18 \%$ of the variation in the bulked-sample-based approach, respectively (Fig. 2d). The cultivars of ssp. chinensis, japonica, and oleifera were plotted closely, apart from the cultivars of ssp. pekinensis and ssp. rapa. The cultivars in ssp. rapa were scattered along the first axis, compared to their position in the plots in the individualsample-based approach. As a result, 'Maruba-komatsuna'

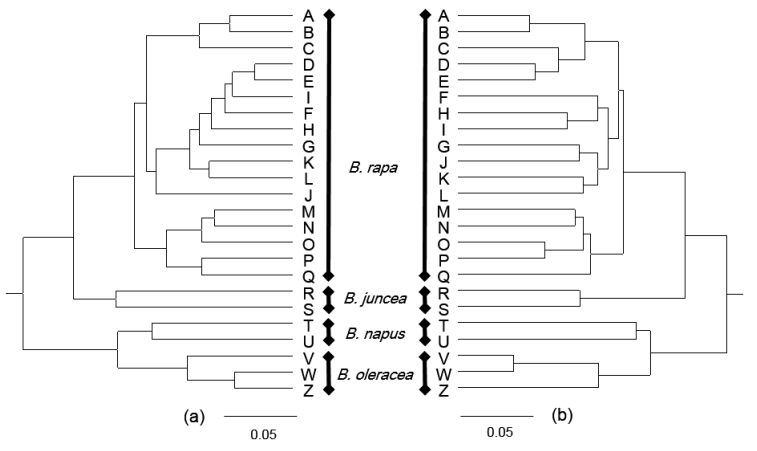

Fig. 3. UPGMA trees based on genetic distances estimated using RAPD and ISSR among 24 cultivars. a: Individual-based approach, b: bulked-samples-based approach. Each cultivar is indicated by a plant ID (defined in Table 1). The scale bars represent genetic distances.

(E) and 'Kiso-benikabu' (D) were close to 'Tokyo-bekana' (C) and were plotted without a clear division between ssp. pekinensis and ssp. rapa.

The UPGMA tree, based on the individual- and bulked-samples data, resulted in a clear separation of the four Brassica species (Fig. 3). On the whole, the topologies of both the trees were similar to each other although some clustering in the dendrograms was not absolutely 
identical between them. In the bulked-sample-based approach, 'Maruba-komatsuna' (D) and 'Kiso-benikabu' (E) in ssp. rapa were clustered with ssp. pekinensis cultivars although the cultivars in ssp. pekinensis and ssp. rapa formed their own cluster, in the individual-based approach. In addition, in the bulked-samples-based approach, ssp. narinosa $(\mathrm{O}$ and $\mathrm{P})$ were clustered closer to each other compared to locations in the individual-based approach.

Consequently, although some disagreements were observed as mentioned above, the results of PCoA and UPGMA, obtained using the individual- and bulkedsamples-based approaches, reflected the genome composition and had a relatively similar pattern.

\section{Discussion}

To assess the genetic relationships among Brassica cultivars, including those among the out-crossing species, the number of individuals sampled should be sufficiently large, so that they can capture the heterogeneity within a cultivar. In the bulk method, use of a small sample size produces distortion in the detection of rare alleles (Divaret et al. 1999, Mailer and May 1999, Fu et al. 2003). Moreover, if the sample size of the bulk becomes large, a large difference in banding pattern will no longer be found (Divaret et al. 1999). This shows the importance of evaluating the number of individuals, which includes the variance of the variety used for analysis (Yu and Pauls 1993). Our previous study (Wakui et al. 2009) with local varieties of turnip indicated that six to eight individuals per cultivar were enough to calculate an accurate estimate of similarity with the individual-based approach.

Based on the above-mentioned results, we used eight individuals per cultivar for the RAPD and ISSR analyses in this study. The expected heterozygosity values showed relatively low genetic variation within the cultivars, compared to that reported previously on other out-crossing species (Durka et al. 2005, Flajoulot et al. 2005). AMOVA also revealed similar a result for variation among individuals within a cultivar. The isozyme loci of B. campestris (B. rapa) and B. oleracea also revealed low genetic variance within the cultivars (Simonsen and Heneen 1995). On the other hand, most of the variation was contributed to the genetic variance among the cultivars, showing that the genetic differentiation of each cultivar is progressing. An almost similar distribution was obtained after PCoA, based on the genetic similarity matrix of individual- and bulked-samples data. $B$. napus were grouped closer to $B$. oleracea than to $B$. rapa; this distribution was identical to the results reported by Thormann et al. (1994) and Liu and Wang (2006). The UPGMA trees also revealed that both the clusters based on individual- and bulked-samples data had an almost similar pattern reflecting genome composition at the species level. However, the grouping of taxa within the $B$. rapa cluster containing six subspecies indicated that 'Maruba-komatsuna' (D) and 'Kiso-benikabu' (E) were situated close to ssp. pekinensis in the bulked-samples-based approach in PCoA. Also, in UPGMA, this result was reflected by the dendrogram in the bulkedsamples-based approach. In addition, 'Bitamin-na' $(\mathrm{O})$ in ssp. narinosa, which formed a small cluster with 'Tijimina' (P) of same subspecies in the bulked-samples-based approach, was connected with a cluster consisting of both the cultivars of ssp. chinensis and japonica in the individual-based approach. It is inferred that these differences in the genetic structure between both the approaches are caused by the degree of genetic diversity existing among individuals within a cultivar. As the result presented in Fig. 1 shows, the bulked-samplesbased approach simplifies the marker profile of an individual cultivar without rare fragments because it favors the detection of consensus fragments in each cultivar. Among the materials used in this study, some cultivars in which the heterozygosity was relatively high, changed the genetic distributions more or less, and the results of PCoA and UPGMA tree between both the approaches are similar but different in their details. Therefore, the bulked-samples-based approach is useful for showing the genetic relationship based on the detected fragments that take precedence over common alleles, within the genetic diversity among individuals within each variety.

These comparative findings indicate that each cultivar could be profiled by RAPD and ISSR markers and classified similarly in the individual- and bulkedsamples-based approaches. This favors high correlation coefficients between the similarity measures for individual- and bulked-samples data, as shown in our previous study (Wakui et al. 2009). Especially, eight individuals within a cultivar, which were determined based on the results of a previous study (Wakui et al. 2009), appear to be appropriate and include the variation within a cultivar, because the expected heterozygosity value within each cultivar was low (Table 1). An advantage of a high-throughput system for accurately characterizing the genetic diversity among populations using bulked DNA as templates was described previously (Segovia-Lerma et al. 2003, Muminović et al. 2005, Wang et al. 2008, Keivani et al. 2010, Taški-Ajduković et al. 2014). However, the method for determining the number of individuals required for preparing the bulk DNA and the result of the comparison to the individual-based approach were not described. In the present study, we compared the individual- and bulked-samples-based approaches to characterize the genetic variability and relationships among the population of out-crossing species on the basis of the number of individuals previously determined with well-grounded approaches. This study empirically showed that a suitable number of individuals treated in the individual-based approach could be reduced to eight 
individuals from 37 individuals per cultivar in Brassica species. Furthermore, in the bulked-based approach, the genetic variability and relationships among and within species can be elucidated with accuracy in Brassica species.

\section{Acknowledgements}

We thank Dr. Fujimaki for constructive comments on an earlier version of the manuscript.

\section{References}

Agarwal, M., Shrivastava, N. and Padh, H. 2008. Advances in molecular marker techniques and their applications in plant sciences. Plant Cell Rep. 27: 617-631.

Dasgupta, N., Nandy, P., Sengupta, C. and Das, S. 2018. Genetic variation in relation to adaptability of three mangrove species from the Indian Sundarbans assessed with RAPD and ISSR markers. J. For. Res. 29: 301-310.

Dias, P. M. B., Pretz, V. F., Dall'Agnol, M., Schifino-Wittmann, M. T. and Zuanazzi, J. A. 2008. Analysis of genetic diversity in the core collection of red clover (Trifolium pratense) with isozyme and RAPD markers. Crop Breed. Appl. Biotech. 8: 202-211.

Divaret, I., Margalé, E. and Thomas, G. 1999. RAPD markers on seed bulks efficiently assess the genetic diversity of a Brassica oleracea L. collection. Theor. Appl. Genet. 98: 1029-1035.

Dulson, J., Kott, L. S. and Ripley, V. L. 1998. Efficacy of bulked DNA samples for RAPD DNA fingerprinting of genetically complex Brassica napus cultivars. Euphytica 102: 65-70.

Durka, W., Bossdorf, O., Prati, D. and Auge, H. 2005. Molecular evidence for multiple introductions of garlic mustard (Alliaria petiolata, Brassicaceae) to North America. Mol. Ecol. 14: 1697-1706.

Excoffier, L., Smouse, P. E. and Quattro, J. M. 1992. Analysis of molecular variance inferred from metric distances among DNA haplotypes: Application to human mitochondrial DNA restriction data. Genetics 131: 479-491.

Fernández, M. E., Figueiras, A. M. and Benito, C. 2002. The use of ISSR and RAPD markers for detecting DNA polymorphism, genotype identification and genetic diversity among barley cultivars with known origin. Theor. Appl. Genet. 104: 845-851.

Flajoulot, S., Ronfort, J., Baudouin, P., Barre, P., Huguet, T., Huyghe, C. and Julier, B. 2005. Genetic diversity among alfalfa (Medicago sativa) cultivars coming from a breeding program, using SSR markers. Theor. Appl. Genet. 111: 1420-1429.

Fu, Y.-B., Guerin, S., Peterson, G., Carlson, J. E. and Richards, K. W. 2003. Assessment of bulking strategies for RAPD analyses of flax germplasm. Genet. Resour. Crop Evol. 50: 743-746.

Ghérardi, M., Mangin, B., Goffinet, B., Bonnet, D. and Huguet, T. 1998. A method to measure genetic distance between allogamous populations of alfalfa (Medicago sativa) using RAPD molecular markers. Theor. Appl. Genet. 96: 406-412.

Gower, J. C. 1966. Some distance properties of latent root and vector methods used in multivariate analysis. Biometrika 53: 325-338.

Han, Y. and Wang, H.-Y. 2010. Genetic diversity and phylogenetic relationships of two closely related northeast China Vicia species revealed with RAPD and ISSR markers. Biochem. Genet. 48: 385-401.

Kalia, P., Saha, P. and Ray, S. 2017. Development of RAPD and ISSR derived SCAR markers linked to XcalBo gene conferring resistance to black rot disease in cauliflower (Brassica oleracea var. botrytis L.). Euphytica 213: 232.

Keivani, M., Ramezanpour, S. S., Soltanloo, H., Choukan, R., Naghavi, M. and Ranjbar, M. 2010. Genetic diversity assessment of alfalfa (Medicago sativa L.) populations using AFLP markers. Aus. J. Crop Sci. 4: 491-497.

Kölliker, R., Jones, E. S., Jahufer, M. Z. Z. and Forster, J. W. 2001. Bulked AFLP analysis for the assessment of genetic diversity in white clover (Trifolium repens L.). Euphytica 121: 305-315.

Kongkiatngam, P., Waterway, M. J., Coulman, B. E. and Fortin, M. G. 1996. Genetic variation among cultivars of red clover (Trifolium pratense L.) detected by RAPD markers amplified from bulk genomic DNA. Euphytica 89: 355-361.

Lázaro, A. and Aguinagalde, I. 1998. Genetic diversity in Brassica oleracea L. (Cruciferae) and wild relatives $(2 n=18)$ using RAPD Markers. Ann. Bot. 82: 829-833.

Liu, A. H. and Wang, J. B. 2006. Genomic evolution of Brassica allopolyploids revealed by ISSR marker. Genet. Resour. Crop Evol. 53: 603-611.

Mailer, R. J. and May, C. E. 1999. Heterogeneity of random amplified polymorphic DNA sequences in individual seedlings and bulked samples of four cultivars of Brassica napus. Plant Breed. 118: 465-470.

Michelmore, R. W., Paran, I. and Kesseli, R. V. 1991. Identification of markers linked to disease-resistance genes by bulked segregant analysis: A rapid method to detect markers in specific genomic regions by using segregating populations. Proc. Natl. Acad. Sci. U.S.A. 88: 9828-9832.

Muminović, J., Merz, A., Melchinger, A. E. and Lübberstedt, T. 2005. Genetic structure and diversity among radish varieties as inferred from AFLP and ISSR analyses. J. Am. Soc. Hortic. Sci. 130: 79-87.

Nei, M. 1972. Genetic distance between populations. Am. Nat. 106: 283-292.

Peakall, R. and Smouse, P. E. 2012. GENALEX 6: Genetic analysis in Excel. Population genetic software for teaching and research. Mol. Ecol. Notes 6: 288-295.

Puecher, D. I., Robredo, C. G., Rios, R. D. and Rimieri, P. 2001. Genetic variability measures among Bromus catharticus Vahl. populations and cultivars with RAPD and AFLP markers. Euphytica 121: 229-236.

Raimondo, F. M., Scialabba, A., Zecca, G., Grassi, F., Casazza, G. and Minuto, L. 2012. Genetic diversity in the endangered Sicilian endemic Brassica rupestris: Proposals for a conservation strategy. Plant Biosyst. 146: 847-856.

Rogers, S. O. and Bendich, A. J. 1988. Extraction of DNA from Plant Tissues. In: Galvin, S. B. and Schilperoort, R. A. (eds.). Plant Molecular Biology Manual A6. Kluwer Academic Publishers, Dordrecht. pp. 1-10.

Segovia-Lerma, A., Cantrell, R. G., Conway, J. M. and Ray, I. M. 2003. AFLP-based assessment of genetic diversity among nine alfalfa germplasms using bulk DNA templates. Genome 46: 51-58.

Semagn, K., Bjørnstad, Å. and Ndjiondjop, M. N. 2006. An overview of molecular marker methods for plants. Afr. J. Biotechnol. 5: 2540-2568.

Simonsen, V. and Heneen, W. K. 1995. Genetic variation within and among different cultivars and landraces of Brassica campestris L. and B. oleracea L. based on isozyme. Theor. Appl. Genet. 91: 346-352.

Sudupak, M. A. 2004. Inter and intra-species inter simple sequence repeat (ISSR) variations in the genus Cicer. Euphytica 135: 229-238.

Sultana, S. S. and Alam, S. S. 2016. SSR and RAPD-based genetic diversity in cotton germplasms. Cytologia 81: 257-262.

Tamura, K., Dudley, J., Nei, M. and Kumar, S. 2007. MEGA4: Molecular evolutionary genetics analysis (MEGA) software version 4.0. Mol. Biol. Evol. 24: 1596-1599.

Taški-Ajduković, K., Nagl, N., Milić, D., Katić, S. and Zorić, M. 2014. Genetic variation and relationship of alfalfa populations and 
their progenies based on RAPD markers. Cent. Eur. J. Biol. 9: 768-776.

Thormann, C. E., Ferreira, M. E., Camargo, L. E. A., Tivang, J. G. and Osborn, T. C. 1994. Comparison of RFLP and RAPD markers to estimating genetic relationships within and among cruciferous species. Theor. Appl. Genet. 88: 973-980.

Nagaharu, U. 1935. Genome analysis of Brassica with special reference to the experimental formation of B. napus and its peculiar mode of fertilization. Jpn. J. Bot. 7: 389-452.

Verma, V., Thakur, A. K., Singh, B. K., Chauhan, D. K., Singh, K. H. and Chauhan, J. S. 2016. Assessment of genetic fidelity in vitro regenerated plants of Brassica juncea (L.) Czern \& Coss. using RAPD and ISSR markers. Int. J. Biotechnol. 15: 120-123.

Wakui, K., Iwata, H., Takahashi, Y., Takahata, Y. and Fujigaki, J. 2009. Assessment of the congruity on genetic relationships and variations in Japanese turnip (Brassica rapa ssp. rapa) culti- vars revealed by individual-based and bulked-samples-based approaches using RAPD and ISSR markers. Breed. Sci. 59: 447-452.

Wang, N., Kitamoto, N., Ohsawa, R. and Fujimura, T. 2008. Genetic diversity of radish (Raphanus sativus) germplasms and relationships among worldwide accessions analyzed with AFLP markers. Breed. Sci. 58: 107-112.

Wu, C. J., Cheng, Z. Q., Huang, X. Q., Yin, S. H., Cao, K. M. and Sun, C. R. 2004. Genetic diversity among and within populations of Oryza granulata from Yunnan of China revealed by RAPD and ISSR markers: Implications for conservation of the endangered species. Plant Sci. 167: 35-42.

Yu, K. and Pauls, K. P. 1993. Rapid estimation of genetic relatedness among heterogeneous populations of alfalfa by random amplification of bulked genomic DNA samples. Theor. Appl. Genet. 86: 788-794. 